\title{
A criação em cena: memórias, percepções e imagens que emergem do corpo que dança.
}

\author{
Autor: Rosely Conz \\ Universidade Estadual de Campinas (UNICAMP) - Mestrando \\ Pesquisa em Andamento \\ Artes da Cena - Orientador: Profa. Dra. Júlia Ziviani Vitiello \\ Atuação profissional - artística
}

Resumo: Nesse projeto de mestrado, busca-se observar as interferências das memórias na criação e interpretação em dança contemporânea. Através da pesquisa teórico-prática, o objetivo é entender as possíveis relações entre as memórias do artista -sensações, imagens, aprendizados e percepções e o processo de criação em dança. Este estudo necessariamente estabelece uma relação entre perceber, observar e experimentar e terá como uma de suas resultantes a criação e apresentação de um solo em dança contemporânea. A metodologia proposta oferece suporte por meio de três pilares que se integram durante o processo: a técnica de dança ou habilidades corporais, as referências poéticas e os procedimentos de improvisação e composição, como ferramentas essenciais para a realização da criação.

Palavras-chave: educação somática, memória corporal, processo de criação

Title: The creation in focus: memories, perceptions and images that emerge from the body that dances.

Abstract: This graduate project observes the interferences of memories during the creation and performance of contemporary dance. Through theoretical and practical research, the objective is to understand the possible relation between the memories of the artist, sensation, images, experience and perception, and the creative process in dance. This project establishes a relationship between observation and practice and will have as one of it's results the creation and presentation of a contemporary dance solo. The methodology proposed offers three foundation pillars that integrate during the process: the dance technics or corporal skills, poetic references, composition and improvisational procedures as essential tools for the creative process. Keywords: body memory, creative process, somatics education

Título: La creación en escena: memorias, percepciones e imagenes que surgen del cuerpo que danza.

Resumen: En ese proyecto de maestría, busca observar las interferencias de las memorias en interpretación y creación en danza contemporánea. Por medio de la pesquisa teórica y práctica, el objetivo es entender las posibles relaciones entre las memorias del artista - sensaciones, imágenes, aprendizaje y percepciones - y el proceso de creación en danza. Este estudio necesariamente establece una relación entre percibir, observar y experimentar y tendrá como uno de sus resultados la creación y la presentación de un solo en danza contemporánea. La metodología propuesta ofrece soporte por medio de tres pilares que se integran mientras el proceso: la técnica de danza o habilidades corporales, las referencias poéticas y los procedimientos de improvisación y composición, como herramientas esenciales para la realización de la creación.

Palabras-clave: educación somática, memoria corporal, proceso de creación. 


\section{Introdução}

Memórias do corpo. Corpo-memória. Memória corporal. Tantos nomes-conceitos para o que parece ser acessível pela dança. Essa pesquisa busca discutir sobre esse(s) tema(s), ultimamente tão em voga nas artes da cena. Para tanto, estão sendo utilizados estudos feitos por artistas da dança e também por autores que têm acompanhado o caminho dessa pesquisa. É importante dizer que não estabeleci uma única linha - neurociência, filosofia, fenomenologia, busquei autores que respondessem às questões surgidas na prática. Assim, tenho como autores principais para instrumentalizar a pesquisa sobre memória Ivan Izquierdo, Antônio Damásio e a obra "Body Movement, Metaphor and Movement”, que reúne artigos sobre a memória corporal. A tese de doutorado da professora Júlia Ziviani Vitiello assim como outras teses sobre o assunto também fazem parte do arsenal teórico.

Clarice Lispector aparece para dar o tom poético das discussões e para, com seus textos, sugerir modos de transformar as memórias em criação artística. No livro “A Descoberta do Mundo” (1984), a autora compartilha diversos momentos-memórias e diz da impossibilidade de fugir deles:

Estas coisas que ando escrevendo aqui não são, creio, propriamente crônicas (...) Nesta coluna estou de algum modo me dando a conhecer. Perco minha intimidade secreta? Mas que fazer? É que escrevo ao correr da máquina e, quando vejo, revelei certa parte minha. Acho que se escrever sobre o problema da superprodução do café no Brasil terminarei sendo pessoal" (LISPECTOR, 1984, p.137)

Nessa obra, composta por crônicas publicadas no Jornal do Brasil entre os anos de 1967 e 1973, a escritora se expressa de modo mais pessoal contando ao leitor experiências de sua infância e juventude, misturadas aos fatos presentes do cotidiano. Entretanto, apesar de contar-se em seus contos, Clarice não é autobiográfica: "Muita coisa não posso te contar. Não vou ser autobiográfica. Vou ser 'bio' " (LISPECTOR, 1973, p. 73). Ao que Régis explica: "Não era a seqüência factual que lhe importava, mas a força da vida se manifestando, exigindo expressão" (RÉGIS, 2007, p. 115).

Os questionamentos que motivam essa pesquisa surgem, principalmente, da prática. $\mathrm{O}$ desenvolvimento de um processo de criação a partir das memórias do corpo caminha de mãos (pés, braços, cotovelos, cabelos, etc) dadas com teorias sobre o assunto. Escolheu-se observar os hábitos ou os padrões de movimentos ${ }^{1}$ que são aprendidos a partir da prática de uma técnica de dança - o ballet clássico. Essa escolha justifica-se pois, por mais de 20 anos, essa foi a única forma de dançar que conheci. Considerando-se que a experiência é uma somatória de fatos, ideias, pensamentos e sensações, adquiridos por meio do exercício de uma atividade, essa é uma escolha quase sem 
escolha. O que foi aprendido passa a fazer parte do acervo corporal e sua importância se mostra nos gestos e movimentos surgidos espontaneamente ou estimulados por situações, que os trazem à tona por meio dos nossos sentidos corporais. Para o estudo sobre a técnica do ballet clássico, foram utilizados principalmente duas obras: “The Principles of Classical Dance” e "Ballet pedagogy". Essas foram as obras escolhidas pois não se restrigem ao estudo de um método ou escola específica - italiana, russa, francesa, etc - mas tratam do ensino do ballet a partir de seus princípios básicos, conceitos que podem ser considerados universais nessa técnica.

A Ideokinesis constitui o meio para instrumentalizar-me na observação e compreensão dos padrões de movimento que o corpo apresenta enquanto dança. A Ideokinesis "é um método criativo de uso da imaginação e processos mentais para melhorar padrões de movimento" (BERNARD, 2006, p. 24) que objetiva não apenas uma reorganização funcional e estrutural do corpo, mas que também possibilita ampliar a percepção sobre as imagens que surgem durante os movimentos, tanto os que referenciam o próprio método, quanto os que surgem durante as improvisações nos laboratórios de criação.

Neste projeto, a Ideokinesis atua em parceria com as técnicas de balé clássico e contemporânea, já que estas constituem a base de formação artística da pesquisadora. Assim, este método somático ${ }^{2}$ faz parte de um dos três pilares anteriormente citados: a técnica - mas que se tornará também o elo básico entre os pilares técnica/ criação/ poética. Não somente por possibilitar uma percepção e uma organização corporal refinada e eficiente, mas por ensinar ao praticante meios de concentrar-se numa imagem, identificar seu início, percurso e finalização. Deste modo, passa a facilitar o trânsito entre aquilo que acontece internamente, sua manifestação no corpo e sua projeção no ambiente externo.

A proposta de estudar a memória como parte essencial da criação em dança faz com que eu tenha que observar e perceber como os procedimentos cognitivos que aconteceram em meu corpo, como foi meu aprendizado. Neste caso, fica claro que não possuo um objetivo autobiográfico, mas antes integrar dois temas principais - memória do corpo e criação em dança.

\section{Desenvolvimento}

Diversos autores (KOCH (Org.), IZQUIERDO, KANDEL) reconhecem a existência de um tipo específico de memória que relaciona-se de maneira direta com o aprendizado em dança. É o que eles chamam de memória implícita ou memória de procedimento. "Denominam-se memórias procedurais ou memórias de procedimento as memórias de capacidades ou habilidades motoras ou 
sensoriais e o que habilmente chamamos de 'hábitos' "(IZQUIERDO, 2002, p. 23). No aprendizado da dança, a repetição e o exercício são os meios para a formação desse tipo de memória.

A memória de procedimento não é algo exclusivo dos bailarinos. Andar de bicicleta, comer, dirigir um carro... Todas essas ações são aprendidas e classificadas como memórias de procedimento. Entretanto, parece ser na dança que este tipo de memória torna-se algo muito evidente e por isso necessário de ser estudado:

Nós andamos para o escritório, tomamos café, dirigimos nossos carros, etc. O corpo é a companhia silenciosa de todas as nossas atividades e comumente é percebido apenas quando não funciona: por exemplo por causa de dor, ou doença. Na dança, ao contrário, os movimentos do corpo estão em primeiro plano, o bailarino é ao mesmo tempo o ser que move e é movido" (DÁVILA, in KOCH (Org.), 2012, p. 107, tradução da autora do trecho citado $^{3}$ )

O corpo é memória viva, em constante (re)criação. Não é um depositário, um baú de acontecimentos. É corpo presente no momento presente. Assim, dançar as memórias é sempre criar. Estudos demonstram que a memória corporal não é algo que situa-se no passado mas sim é sempre um acontecimento do/ no presente. A memória só pode ser vista, estudada e observada a partir do presente. "O que nós uma vez adquirimos como habilidades, hábitos e experiência tornam-se o que somos hoje; portanto, memória corporal é nosso passado vivo" (FUCHS, in KOCH (org.), 2012, p. 11, tradução pela autora do trecho citado $^{4}$ ). A memória de habilidades ou de procedimentos é uma memória também de sensações. E as sensações só são possíveis de serem lembradas quando são sentidas.

Entretanto durante o estudo me pareceu insuficiente estudar apenas esse tipo de memória. Porque quando o corpo recorda, muitas vezes (quase todas) ocorre um recordar "misturado"- são memórias de diferentes tipos que aparecem e influenciam na criação. Também percebo ser impossível viver o momento que se foi. Afinal, nossa inteligência presente refaz a experiência. Nunca saberemos o que realmente aconteceu pois não temos mais o corpo de antes, só o de hoje.

\section{Justificativa}

Antes de começar a caminhar, fiz as malas. Carreguei-as com argumentos, objetivos, livros, livros e livros... Alguns sobre memória, outros sobre a Ideokinesis, ballet e sobre processos de criação. Entre esses últimos, destaco as obras "The moment of the movement" e "The viewpoints book". O projeto de pesquisa foi aprovado e começou (ou recomeçou?) o caminhar. Percebo que o projeto foi apenas uma pausa no meio desse caminho. Este já vem sendo trilhado desde os seis anos quando comecei a fazer aulas de ballet e perguntar (perguntadeira que eu era!) à minha professora por que 
ela só contava até oito ou por que só podíamos usar a barra de dois modos diferentes, ou por que eu não podia fazer os saltos no começo da aula... Foram anos de prática dessa técnica, aos quais se seguem outros tantos (não tantos quanto os anteriores) de questionamentos e reflexões sobre ela. $\mathrm{O}$ corpo que aprendeu continua a ser "perguntador".

Mas nesse momento, paradoxalmente, a sala vazia assusta e inquieta. O corpo que parecia ter tanto a dizer, emudece diante do desafio de contar-se, encontrar-se... E, quase arrependida, eu questiono por que mais um solo de dança contemporânea? Explico: O projeto de pesquisa apresentado ao programa de Mestrado em Artes da Cena em 2011 propôs a criação de um solo de dança a partir do estudo da memória corporal.

Imposto o desafio, como lidar com ele agora? Um dos caminhos possíveis foi pensar, junto com “autores amigos", as razões e possibilidades dessa escolha, que também parece comum na chamada modernidade. Durante a pesquisa, ainda em curso, encontrei ideias que busquei organizar e compartilhar nesse texto.

Identificou-se, a partir da leitura do texto "O solo de dança no século XX: entre proposta ideológica e estratégia de sobrevivência" de Eugênia Casini Ropa, alguns apontamentos que podem explicar o grande número de solos produzidos no século XXI.

Primeiramente a proposta de danças-solo mostra-se uma necessidade de mercado. A insuficiência de recursos financeiros destinados a arte tanto na esfera pública quanto acadêmica, parece obrigar os pesquisadores a permanecerem sozinhos. Transportar, produzir, vestir e remunerar um solo é muito mais barato que fazer o mesmo para um grupo. E surgem então os editais, festivais, concursos e teses que fomentam esse tipo de obra artística. Não quero dizer que o solo seja uma proposta artística "menor"ou "ruim". Entretanto, essa deveria ser uma escolha e não uma imposição diante da falta de recursos, espaços, incentivos, etc.

Mas houve também o desejo de encontrar-me. Teria de ser uma conversa comigo mesma. Pois de que outro modo poderia construir ferramentas e desenvolver procedimentos para ver este corpo repleto de tudo que já aprendeu durante anos e que agora quer criar? Quer recombinar suas memórias de um jeito que, se não novo, ao menos diferente do que fez até agora. "É muito difícil definir o que é criar e o que é a criatividade. Uma criação (...) se trata indefectivelmente da conjunção de memórias de uma maneira que não haviam se combinado antes” (IZQUIERDO, 2011, p. 31). Assim, assumi o risco. Fiquei vulnerável, tive (e tenho) medo. Não quero mais repetir os padrões de movimento, os hábitos que demonstro durante as improvisações. E somente eles me aparecem. Questiono-me: esse é o meu estilo, minha assinatura pessoal? Ou é algo que aprendi 
apenas imitando e desconhecendo o porquê? Conseguirei recombinar as palavras que aprendi? Conseguirei encontrar a origem disso?

Identifico-me com Ana Cristina Colla quando ela diz sobre o seu próprio processo de criação:

\footnotetext{
Entro na sala como se fosse o primeiro dia. Só hoje, só o agora. E o que surge, a voz que fala, vem de anos. Grudada em mim. Agora tenho raiva dela,dessa voz monótona e repetitiva. Sonolenta. Provoco-a. Trago convidados esquisitos, mal educados, que não respeitam as regras. As regras, essas construidas arduamente. Apontando passo a passo como devo seguir. Entrar na sala assim, aquecer assim, música assim, assim,assim, assim (...) Quis fugir. Mas como, se eu propria era minha convidada para esse encontro?" (COLLA, 2010, p. 36)
}

Apesar de ser meu principal convidado para o caminhar da pesquisa, chego a duvidar do corpo. Mas como, se ele é única certeza que tenho? Devo, então, olhar novamente nas malas que fiz. Certamente encontrarei lá os meios de que preciso para confiar. Pois para olhar para as memórias, reconhecê-las e, então, transformá-las em ato artístico são necessários alicerces e os meus, acredito, foram bem escolhidos.

\section{Objetivos}

Pesquisar e refletir, através do desenvolvimento de um processo de criação, sobre a interferência das memórias na arte da dança, reconhecendo que o processo de formação do bailarino influencia em suas criações e atuações.

\section{Métodos}

Os procedimentos criativos que utilizei durante a pesquisa foram sendo descobertos, inventados, colados, emprestados e utilizados durante a criação do solo proposto no projeto de pesquisa. A experiência mostra que é muito difícil determinar o início ou o fim de um procedimento, de uma descoberta. A criação assemelha-se mais à uma espiral, sem início ou fim, mas em constante movimento.

As reflexões teóricas alimentando a prática e a prática impulsionando novas pesquisas teóricas. Essa é a metodologia que tem sustentado o estudo até aqui.

\section{Resultados}

A teoria só faz sentido nessa pesquisa quando vivenciada. Assim, dinâmicas de improvisação são tão importantes quanto a leitura de um texto. Dessa forma foi construído o caminho percorrido até aqui, através da relação constante entre teoria e prática. Algumas respostas parecem possíveis para o tema da memória e os estudos esclarecem dúvidas relacionadas a hábitos motores, cognitivos, etc. 
A obra artística, entretanto, parece criar novas questões que só serão respondidas pelo corpo. Talvez essa seja a função da obra de arte: criar movimento, inquietação.

A prática da Ideokinesis possibilitou reconhecer os padrões de movimento que são característicos dessa pesquisadora. Percebeu-se que muitos desses padrões são resultantes da extensa prática da técnica de dança clássica, realizada por mais de 16 anos, em especial os que se relacionam a utilização e alinhamento dos tornozelos e pés. As improvisações estruturadas a partir desse tema constituem o tema para a criação nesse momento e ajudam na composição de pequenos estudos coreográficos que norteiam a composição final. Pesquisa de trilha sonora, objetos cênicos, figurino caminham em paralelo com a escrita da dissertação.

Além disso, no centro desse processo está a percepção sobre os movimentos que geram sensações e imagens, e estas, alimentam novos movimentos. Imagens que surgem repletas de cores, cheiros, sons. E a pergunta: Como fazer a transferência da imagem para o movimento? Somente o conhecimento aguçado desse que é o lugar da dança, o corpo, me permite essa tarefa. Modulações finas de tônus, uso de articulações, respiração, dinâmicas de movimento diferentes - esses são os meios necessários para tornar a imagem visível na dança.

\section{Bibliografia}

BERNARD, Andre. Ideokinesis: A creative Approach to Human Movement \&Body Alignment. Berkeley: North Atlantic Books, 2006

BLOM, Lynne Anne; CHAPLIN, L. Tarin. The moment of movement: dance improvisation. Cecil Court: Dance Books, 1988.

BOGART, Anne.; LANDAU, Tina. The Viewpoints book - A practical guide of Viewpoints and composition. New York: Theatre Communications Group, 2005.

COLLA, Ana Cristina; SPERBER, Suzi Frankl (orient.). Caminhante, não ha caminho. Só rastros. 2010. 205 p. Tese (doutorado) - Universidade Estadual de Campinas, Instituto de Artes, Campinas, SP. Disponível em: <http://libdigi.unicamp.br/document/?code=000615904>. Acesso em: 01 jul 2012.

DAMÁSIO, Antonio. E o Cérebro criou o Homem. São Paulo: Companhia das Letras, 2011. Tradução: Laura Teixeira Motta.

FOSTER, Rory. Ballet Pedagogy: the art of teaching. Florida: The university Press of Florida, 2010.

FORTIN, S. "Educação Somática: Novo ingrediente da formação prática em dança" In: Cadernos do GIPE-CIT, 2, 1999, 40-55. Tradução de Márcia Strazzacappa 
IZQUIERDO, Ivan. Memória. Porto Alegre: Artmed, 2002

. Somos nuestra memória. Buenos Aires: Libros Del Zorzal, 2011.

KANDEL, Eric. Em busca da memória: o nascimento de uma nova ciência da mente. São Paulo:

Companhia das Letras, 2009

KOCH, Sabine C.; FUCHS, Thomas; SUMMA, Michela; MÜLLER, Cornelia (Org.). Body Memory, Metaphor and Movement. Amsterdam/Philadelphia: John Benjamins Publishing Company, 2012.

LAWSON, Joan; CRICKMAY, Anthony. The principles of classical dance: with photographs of Anthony Dowell by Anthony Crikmay. New York, N.Y.: Alfred A. Knopf, 1980, c1979.

LISPECTOR, Clarice. Água Viva. Rio de Janeiro: Arte Nova, 1973. . A descoberta do mundo. Rio de Janeiro: Nova Fronteira, 1984.

RÉGIS, Sônia. Uma escritora amadora. Ângulo 111, out./dez., 2007, p. 112-115. Acesso através do site www.fatea.br/angulo em 12/05/2011.

ROPA, Eugênia Cassini. O solo de dança no século XX: entre proposta ideológica e estratégia de sobrevivência. In: Urdimento - Revista de Estudos em Artes Cênicas/Universidade do Estado de Santa Catarina. Programa de Pós-graduação em Teatro - Vol.I, n.12, Março de 2009. Florianópolis: UDESC/CEART. p. 61 a 72

ZIVIANI VITIELLO, Júlia. Dança: memória nos corpos cênicos. Campinas, SP: tese (doutorado) Universidade Estadual de Campinas, Faculdade de Educação, 2004.

\footnotetext{
${ }^{1}$ Considero como "padrões de movimento" os movimentos que após serem apreendidos pelo corpo, estabelecem uma organização própria, gerando sempre a mesma resposta para um determinado estímulo.

${ }^{2}$ Thomas Hanna (1928-1990) define o termo educação somática em 1983 como sendo “ a arte e a ciência de um processo relacional interno entre a consciência, o biológico e o meio ambiente, estes três fatores sendo vistos como um todo agindo em sinergia" (Fortin, 1999, p. 40)

${ }^{3}$ Trecho original: "We walk to the office, drink coffee, drive our car, etc. The body is the silent companion of all our activities and is commonly perceived only when it doesn't work: for example, because of pain, or sickness. In dance, on the contrary, the movements of the body are in the foreground; the dancer is at the same time the mover and the moved."

${ }^{4}$ Trecho original: "What we once have acquired as skills, habits, and experience have become what we can do today; hence, body memory is our lived past"
} 